\title{
A Ternary Inhibitor for X80 Steel Corrosion in Phosphoric Acid Solution
}

\author{
Yanhua Zhu', Liqiang Zhao ${ }^{1, *}$, Pingli Liu ${ }^{1}$, Jia Zhuang ${ }^{2}$, Ming Yang $^{1}$ \\ ${ }^{1}$ State Key Laboratory of Oil \& Gas Reservoir Geology and Exploitation Engineering, Southwest \\ Petroleum University, Chengdu, China, 610500 \\ ${ }^{2}$ School of Materials Science and Engineering, Southwest Petroleum University, Chengdu, China, \\ 610500 \\ *E-mail: zyhswpu@ 163.com
}

doi: $10.20964 / 2018.10 .26$

Received: 2 June 2018 / Accepted: 23 July 2018 / Published: 1 September 2018

\begin{abstract}
A ternary corrosion inhibitor $\left(\mathrm{C}_{14} \mathrm{H}_{7} \mathrm{NaO}_{7} \mathrm{~S}-\mathrm{Mo}-\mathrm{Ce}\right)$ was prepared with alizarin red, sodium molybdate and cerium nitrate, its corrosion inhibition performance for X80 steel in phosphoric acid solution was investigated by chemical and electrochemical methods. Results showed that the inhibitor made up by $1.0 \mathrm{~g} / \mathrm{L}$ alizarin red, $1.0 \mathrm{~g} / \mathrm{L}$ cerium nitrate and $1.0 \mathrm{~g} / \mathrm{L}$ sodium molybdate produced strong synergistic effect, and the inhibition efficiency can reach $99.65 \%$. SEM test showed that the ternary inhibitor formed a compact and complete membrance and effectively prevented the corrosive ions to contact with steel surface. The polarization curve showed that the ternary inhibitor is an anodic corrosion inhibitor. The excellent anti-corrosion efficiency of this ternary inhibitor is attributed to generate binary system of two different substances and successively adsorb on steel surface to produce synergic film.
\end{abstract}

Keywords: ternary corrosion inhibitor, alizarin red, phosphoric acid, X80 steel, synergy

\section{$\underline{\text { FULL TEXT }}$}

(C) 2018 The Authors. Published by ESG (www.electrochemsci.org). This article is an open access article distributed under the terms and conditions of the Creative Commons Attribution license (http://creativecommons.org/licenses/by/4.0/). 